\title{
A multigenerational study on phenotypic consequences of the most common causal variant of HNF1A-MODY
}

\author{
Jarno L. T. Kettunen ${ }^{1,2,3,4}$ (D) Elina Rantala ${ }^{5}$ Om P. Dwivedi ${ }^{2}$ (D) $\cdot$ Bo Isomaa $^{1}$ - Leena Sarelin ${ }^{1} \cdot$ Paula Kokko $^{1,2,4}$. \\ Liisa Hakaste ${ }^{1,2,3,4}$ (D) $\cdot$ Päivi J. Miettinen ${ }^{6,7}$ (D) - Leif C. Groop ${ }^{2,8}$ (D) - Tiinamaija Tuomi ${ }^{1,2,3,4,8}$ (D)
}

Received: 6 August 2021 / Accepted: 4 October 2021 / Published online: 24 December 2021

(C) The Author(s) 2021, corrected publication 2022

\begin{abstract}
Aims/hypothesis Systematic studies on the phenotypic consequences of variants causal of HNF1A-MODY are rare. Our aim was to assess the phenotype of carriers of a single HNF1A variant and genetic and clinical factors affecting the clinical spectrum. Methods We conducted a family-based multigenerational study by comparing heterozygous carriers of the HNF1A p.(Gly292fs) variant with the non-carrier relatives irrespective of diabetes status. During more than two decades, 145 carriers and 131 noncarriers from 12 families participated in the study, and 208 underwent an OGTT at least once. We assessed the polygenic risk score for type 2 diabetes, age at onset of diabetes and measures of body composition, as well as plasma glucose, serum insulin, proinsulin, C-peptide, glucagon and NEFA response during the OGTT.

Results Half of the carriers remained free of diabetes at 23 years, one-third at 33 years and $13 \%$ even at 50 years. The median age at diagnosis was 21 years (IQR 17-35). We could not identify clinical factors affecting the age at conversion; sex, BMI, insulin sensitivity or parental carrier status had no significant effect. However, for $1 \mathrm{SD}$ unit increase of a polygenic risk score for type 2 diabetes, the predicted age at diagnosis decreased by 3.2 years. During the OGTT, the carriers had higher levels of plasma glucose and lower levels of serum insulin and C-peptide than the non-carriers. The carriers were also leaner than the non-carriers (by $5.0 \mathrm{~kg}, p=0.012$, and by $2.1 \mathrm{~kg} / \mathrm{m}^{2}$ units of BMI, $p=2.2 \times 10^{-4}$, using the first adult measurements) and, possibly as a result of insulin deficiency, demonstrated higher lipolytic activity (with medians of NEFA at fasting $621 \mathrm{vs} 441 \mu \mathrm{mol} / \mathrm{l}, p=0.0039$; at 120 min during an OGTT 117 vs $64 \mu \mathrm{mol} / 1, p=3.1 \times 10^{-5}$ ).

Conclusions/interpretation The most common causal variant of HNF1A-MODY, p.(Gly292fs), presents not only with hyperglycaemia and insulin deficiency, but also with increased lipolysis and markedly lower adult BMI. Serum insulin was more discriminative than C-peptide between carriers and non-carriers. A considerable proportion of carriers develop diabetes after young adulthood. Even among individuals with a monogenic form of diabetes, polygenic risk of diabetes modifies the age at onset of diabetes.
\end{abstract}

Keywords Age at onset · Glucagon - HNF1A-MODY · Insulin deficiency · Lipolysis · Maturity-onset diabetes of the young $($ MODY $) \cdot$ MODY $3 \cdot$ Monogenic diabetes $\cdot$ NEFA $\cdot$ Polygenic risk score for type 2 diabetes

Tiinamaija Tuomi tiinamaija.tuomi@hus.fi

Folkhälsan Research Center, Helsinki, Finland

2 Institute for Molecular Medicine Finland (FIMM), University of Helsinki, Helsinki, Finland

3 Department of Endocrinology, Abdominal Center, Helsinki University Hospital, Helsinki, Finland

4 Research Programs Unit, Clinical and Molecular Metabolism, University of Helsinki, Helsinki, Finland
5 Vantaa Healthcare Center, Vantaa, Finland

6 New Children's Hospital, Pediatric Research Center, University of Helsinki and Helsinki University Hospital, Helsinki, Finland

7 Research Programs Unit, Molecular Neurology, and Biomedicum Stem Cell Center, University of Helsinki, Helsinki, Finland

8 Lund University Diabetes Center, Department of Clinical Sciences Malmö, Lund University, Malmö, Sweden 


\section{Research in context}

\section{What is already known about this subject?}

- A group of monogenic diabetes, MODY, is characterised by insulin deficiency and early onset

- $\quad$ The reported MODY phenotype is largely based on individuals with suggestive clinical features, although not all individuals with pathogenic MODY variants develop the characteristic young-onset diabetes

\section{What is the key question?}

- Could a family-based approach refine the phenotype associated with HNF1A p.(Gly292fs), the most common MODY variant?

\section{What are the new findings?}

- One-third of the variant carriers were free of diabetes at 33 years and $13 \%$ at 50 years of age

- The carriers were $5 \mathrm{~kg}$ leaner than related non-carriers at their first adult examination, presumably as a result of an insulin secretory defect

- A high polygenic risk score for type 2 diabetes advanced the age at diagnosis of monogenic diabetes

\section{How might this impact on clinical practice in the foreseeable future?}

- As increasing numbers of individuals undergo genetic testing and incidental genetic findings become more prevalent, the phenotypic spectrum associated with monogenic variants will widen

\section{Abbreviations}

FPG

GWAS

ISI

MWU

PPP-Botnia Study

T2D-PRS
Fasting plasma glucose

Genome-wide association study

Insulin sensitivity index

Mann-Whitney $U$ test

Prevalence, prediction and prevention of diabetes-Botnia Study

Polygenic risk score for type 2 diabetes

\section{Introduction}

Subtypes of monogenic diabetes called MODY result from rare single-gene variants (reviewed in $[1,2]$ ). MODY was initially defined as an autosomal dominant young-onset nonobese form of non-insulin-dependent diabetes [3, 4]. These features determining patient selection for the first gene discovery studies [5-8] still guide diagnostic testing [9, 10]. However, the phenotype-based selection bypasses the heterogeneous presentation of MODY [9, 11-13], and the reported gene-disease association can be subject to ascertainment bias in at least two ways. First, carriers of pathogenic MODY variants without diabetes or typical phenotype have often not been included in studies. Second, comparing carriers only with patients with polygenic forms of diabetes can lead to misinterpretations regarding the monogenic variant. For example, the level of insulin sensitivity in MODY caused by variants in HNF 1A (HNF1A-MODY) depends on the comparator group and their genetic background, perhaps irrespective of $H N F 1 A$

altogether [14-16]. And although individuals with HNF1AMODY are more sensitive to sulfonylureas than those with type 2 diabetes [17], their beta cell response to sulfonylureas is similar to that in control individuals without diabetes $[15,18]$, rendering it unlikely that the MODY variant directly affects sulfonylurea sensitivity.

Therefore, we conducted a family-based study to systematically characterise the phenotype of carriers of HNF1A p.(Gly292fs), the most common causal variant of HNF1AMODY worldwide, by comparing carriers and related noncarriers identified through cascade screening irrespective of their diabetes status. We focused on one variant and used a family-based design to minimise phenotypic variation associated with different genetic and environmental backgrounds. In this study carried out during more than two decades [14], we assessed the time of diabetes onset, and genetic and nongenetic factors affecting it, and explored metabolic features associated with the variant.

\section{Methods}

The Botnia Study has been recruiting individuals with diabetes and their family members in western Finland since 1990 [19], and families with two siblings having type 2 diabetes from all of Finland during 1994-1998. Relatives and spouses without diabetes at baseline [20] as well as individuals with pathogenic MODY variants and their siblings [21] have been invited to follow-up examinations. Since 2014, the 
FINNMODY study has co-ordinated the study of MODY families from the Botnia Study and recruited individuals with suspected or diagnosed MODY (and family members) through: (1) advertisements directed at clinicians and patients; (2) directly contacting diabetes clinics and primary care physicians. The study doctor interviewed the potential probands.

All families consisted of at least two heterozygous carriers of the HNF1A p.(Gly292fs) variant and one non-carrier, who was a first-degree relative of a carrier. The 12 families with 145 carriers and 131 non-carriers (electronic supplementary material $[\mathrm{ESM}]$ Table 1) included three large, previously partially reported families (families B, C and D [14]), now extended by longer follow-up and new family members.

All participants gave their informed consent. The study protocol was approved by the Ethics Committees of Medicine and Paediatrics of the Helsinki University Hospital. A research nurse measured the weight, height, waist and hip circumference, heart rate, blood pressure and fat free mass. The participants filled in a questionnaire on socioeconomic and lifestyle factors, medical history and treatment. The age at diagnosis of diabetes was defined as the earliest occurrence of: (1) a diabetic glucose value at a study visit; (2) a self-reported year of the diagnosis; or (3) an ICD code for diabetes in the national registries (see ESM Methods p. 2).

Some individuals only returned the questionnaire and provided fasting blood samples, which were shipped to a central commercial laboratory (for analysis of fasting plasma glucose $[\mathrm{FPG}], \mathrm{HbA}_{1 \mathrm{c}}$, alanine aminotransferase, serum creatinine, urine AER) and our research laboratory.

As a control group, we used the Prevalence, prediction and prevention of diabetes (PPP)-Botnia Study [22], conducted in the region from which most of the study participants originate $(N=5208 ; n=4928$ with genome-wide association study [GWAS] data).

Metabolic characterisation A total of 208 individuals participated in an OGTT $(1.75 \mathrm{~g} / \mathrm{kg}$, maximum dose $75 \mathrm{~g})$ after a 10 $12 \mathrm{~h}$ fast at least once (109 more than once). Samples for plasma/serum glucose and insulin were drawn at $0,30,60$, 90 and $120 \mathrm{~min}$; for C-peptide, proinsulin, glucagon and $\mathrm{NEFA}$, at 0 and $120 \mathrm{~min}$ (for a subgroup also at $30 \mathrm{~min}$ for C-peptide); for cholesterol, LDL- and HDL-cholesterol, triacylglycerols, creatinine, alanine aminotransferase and GAD autoantibodies, as well as blood $\mathrm{HbA}_{1 \mathrm{c}}$, at fasting. Young children, individuals with $\mathrm{FPG}>10 \mathrm{mmol} / \mathrm{l}$ or a diagnosis of type 1 diabetes, or those consenting only to fasting tests did not undergo an OGTT. AER was estimated from overnight urine collections. The analytic methods are described in ESM Table 2.

Genetic testing To determine the HNF1A p.(Gly292fs) (NM 00545.6:c.872dupC) variant, we sequenced exon 4 of the HNF1A gene by the Sanger method. Some participants had received the genetic diagnosis from the Molecular Genetics Laboratory in Exeter, UK, or the Genome Center of the University of Eastern Finland, Kuopio, Finland.

We calculated a polygenic risk score for type 2 diabetes (T2D-PRS) using GWAS data for 210 known independent type 2 diabetes risk loci according to Mahajan and colleagues [23] (details in ESM Table 3). The results were standardised to have a mean of 0 and SD of 1.

Statistical analysis We compared categorical variables by $\chi^{2}$ test with Yates' continuity correction, and continuous variables by Mann-Whitney $U$ test (MWU), reporting a standard 95\% CI, $p$ value and an estimator of the difference (representing the median of the difference between samples). We report nominal $p$ values and comment if the statistical significance was lost after controlling for multiple comparisons (Benjamini-Hochberg procedure). Except for the analyses of age at diagnosis, all comparisons used first adult values, unless stated otherwise (ESM Table 4 shows the mean adult values during the follow-up). HOMA indices for insulin sensitivity and secretion were calculated by the HOMA2 Calculator (Oxford University 2004, www.dtu.ox.ac.uk/ homacalculator [24, 25]), and composite (Matsuda) insulin sensitivity index (ISI) according to Matsuda and DeFronzo [26]. We used R (version 3.6.3) on RStudio (version 1.2.1335). See the ESM Methods (p. 2) for confirmatory and sex-specific analyses, details and a list of R packages used (p. 3).

\section{Results}

Onset of diabetes As expected, the carriers were diagnosed with diabetes more often ( $83 \%$ vs $\left.13 \%, p<2.2 \times 10^{-16}\right)$, and earlier (median [IQR], 21 [17-35] vs 53 [49-59]; range 7-60 vs $11-78$ years; $\left.p=3.1 \times 10^{-7}\right)$, than the non-carriers. By 40 years of age, 51 of $78(65 \%)$ carriers and one of $78(1 \%)$ non-carriers had diabetes, and the carriers had a 51-fold increased risk of diabetes $\left(95 \%\right.$ CI 16, 160; $p_{\text {Wald }}=2.4 \times$ $10^{-11}$, Cox proportional hazards). In a survival analysis, half of the carriers remained free of diabetes at 23 years, and onethird at 33 years (Fig. 1).

The true age at conversion to diabetes is difficult to verify retrospectively. The family members born in later decades were diagnosed younger than those born earlier, possibly because of increased awareness and systematic screening [27]. Of the 47 carriers free of diabetes (in an OGTT) at the baseline investigation at a median [IQR] age of 18 years [1130], 21 (45\%) developed diabetes during the follow-up at the age of 28 [18-47] years, the eldest at 57 years. The remaining 26 carriers had a median age of 18 [12-33] years at the last study visit, the eldest being 63 years.

We hypothesised that high BMI and poor insulin sensitivity (HOMA insulin sensitivity index [HOMA-IS], or ISI) would lower the age at diagnosis, but no significant association was 
seen (see ESM Results p. 4). On the contrary, among the younger carriers (aged $>13$ years, born after 1975) with more systematic screening, higher BMI at the first visit was associated with later age at diagnosis (Cox regression model, HR 0.86; 95\% CI 0.77, $0.96 ; p=0.0066$; a similar but non-significant difference was also observed using the predicted adult BMI based on the Finnish growth centiles [28]: HR 0.90; 95\% CI 0.808, 1.004; $p=0.060$; $n=41$ ). Rather than protection by higher BMI, more likely the defective insulin secretion resulted in lower BMI and earlier diagnosis among the carriers. This is supported by the fact that the BMI association disappeared after adjusting for fasting Cpeptide (data not shown). After the diagnosis of diabetes, BMI was weakly positively associated with higher $\mathrm{HbA}_{1 \mathrm{c}}$ (linear regression model: $1.06 \mathrm{mmol} / \mathrm{mol}$ [0.098\%] higher median $\mathrm{HbA}_{1 \mathrm{c}}$ for each unit of median BMI, $p=0.00072, n=107$ ).

As diabetes was relatively prevalent also in the noncarriers, we hypothesised that genetic susceptibility to type 2 diabetes might lower the age at onset of diabetes. Indeed, the study participants had a higher T2D-PRS (median 0.10; range -2.4 to 3.6 ; IQR -0.52 to 0.94 ) than the population-based control group (median -0.015 ; range -3.63 to 3.55 ; IQR -0.70 to 0.65 ; between-group difference $0.20 ; 95 \%$ CI $0.074,0.325 ; p=0.0019)$. The T2D-PRS was similar in carriers and non-carriers $(p=0.84)$. T2D-PRS contributed to the onset of (any) diabetes among the participants: in a Cox proportional hazards model, 1 SD unit increase in T2D-PRS increased the risk of diabetes by $28 \%$ (HR 1.28 ; $95 \%$ CI $1.065,1.535 ; p=0.00841$; with the HNF1A carrier status as a significant covariate: HR 22.1, $p<2 \times 10^{-16}$ ). Among the carriers, for $1 \mathrm{SD}$ unit increase of T2D-PRS, the predicted age at diagnosis decreased by 3.2 years in a linear model (also adjusted for the year of birth). See ESM Results (p. 5) for further analyses.

Of note, neither sex (data not shown) nor parental inheritance significantly modified the age at diagnosis (those with paternal inheritance had an insignificant 0.79 -fold risk of diabetes compared with those with maternal inheritance; 95\% CI 0.47, 1.30; Cox proportional hazards).

Metabolic characterisation Plasma glucose was higher and serum insulin and proinsulin concentrations lower in carriers than in non-carriers at fasting and during the OGTT (Table 1, ESM Table 4), compatible with insulin deficiency. The proinsulin:insulin ratio was similar in both groups (ESM Fig. 1), confirming some [14, 29] but not all [30] previous reports. The difference in insulin response was greatest at $30 \mathrm{~min}$, presumably representing a defective first-phase insulin secretion among the carriers [31], and the difference in glucose levels peaked at $90 \mathrm{~min}$. The difference in insulin and proinsulin response was reflected in the C-peptide concentrations at $30 \mathrm{~min}$ but not at $120 \mathrm{~min}$. Further, a regression model (ESM Table 5) showed a diminished glucose responsiveness of insulin secretion in carriers compared with non-carriers (i.e., the non-carriers could produce high levels of serum insulin as a response to high plasma glucose). We also analysed the data restricting the analysis to the last nondiabetic visit of the carriers $(n=23-27)$ and sex- and agematched non-carriers. The differences in glucose, insulin and C-peptide response profiles were similar but smaller than in the main analysis (only the differences in 30 and 60 min insulin were statistically significant).

Although the carriers had significantly better insulin sensitivity (ISI, Table 1), a multivariate linear model showed that the difference was more strongly associated with BMI than the variant carrier status (data not shown).

Body composition and lipidaemia The adult carriers were significantly leaner than the non-carriers (Fig. 2, ESM Tables 4, 6), with a similar height but $5.0 \mathrm{~kg}$ lower weight $(p=0.012)$ and $2.1 \mathrm{~kg} / \mathrm{m}^{2}$ lower BMI $\left(p=2.2 \times 10^{-4}\right)$. The ageand sex-adjusted difference was $-4.6 \mathrm{~kg}$ for weight $(p=0.0059)$ and $-1.8 \mathrm{~kg} / \mathrm{m}^{2}$ for BMI $(p=0.0014)$ (linear regression model). Similarly, the carriers were leaner than age- and sex-matched individuals from the population-based PPP-Botnia Study $\left(-1.67 \mathrm{~kg} / \mathrm{m}^{2}\right.$ with $p=0.0030, n=107$, matched for the closest possible age, median age 38.0 vs 38.0 ).

The differences in body composition between carriers and non-carriers were significant in men but the results in women were in the same direction (weight: $-6.9 \mathrm{~kg}[95 \% \mathrm{CI}-11,-2.2]$, $p=0.0047$ vs $-2.5 \mathrm{~kg}[-6.0,2.7], p=0.41$; BMI: $-2.5 \mathrm{~kg} / \mathrm{m}^{2}$ $[-3.7,-1.2], p=2.4 \times 10^{-4} \mathrm{vs}-1.3 \mathrm{~kg} / \mathrm{m}^{2}[-2.7,0.25]$, $p=0.10$ ). The difference was also attenuated regarding the latest

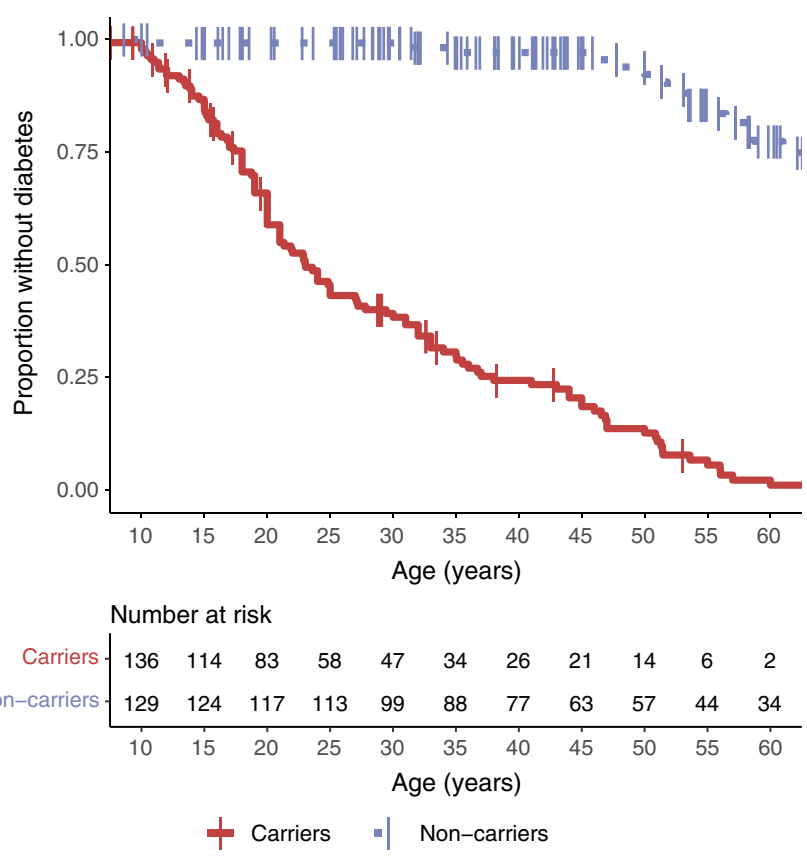

Fig. 1 The survival analysis shows the proportion of carriers (solid red line) and non-carriers (dashed blue line) of HNF1A p.(Gly292fs) not diagnosed with diabetes. As compared with non-carriers, the carriers had an HR of 21 for diabetes (95\% CI 12, 37; $p<2 \times 10^{-16}$ ) 


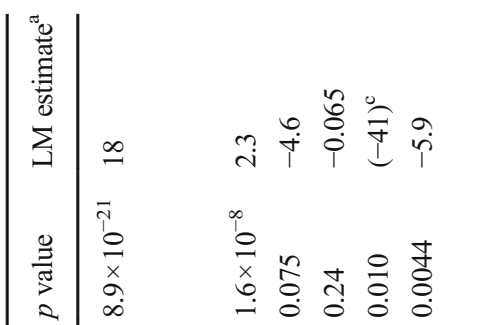

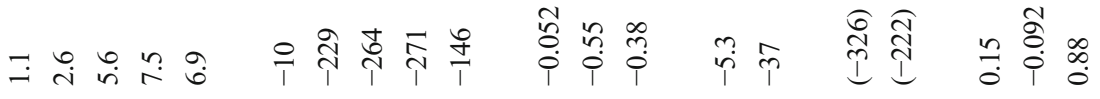

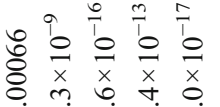

în

io

$\stackrel{0}{i} \stackrel{0}{1}$

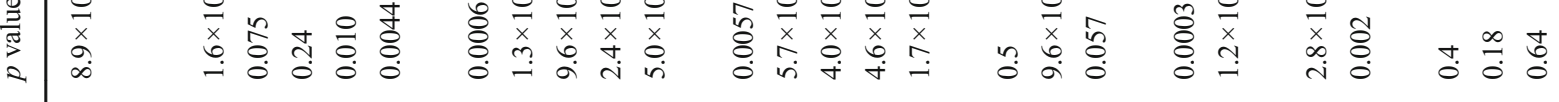

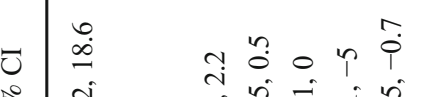

ฯ

$\therefore \overbrace{0}^{\infty}:$

$\stackrel{\substack{a \\ i}}{\substack{1 \\ i}}$

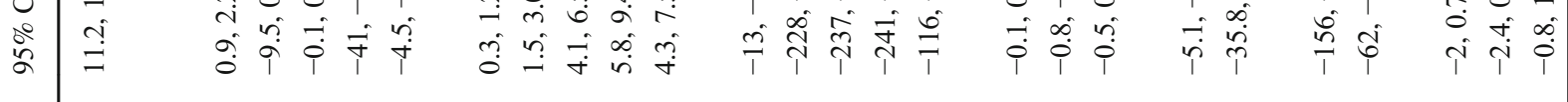

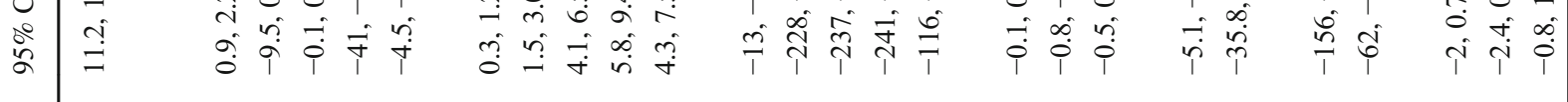

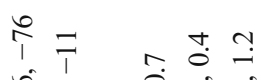

के

לos

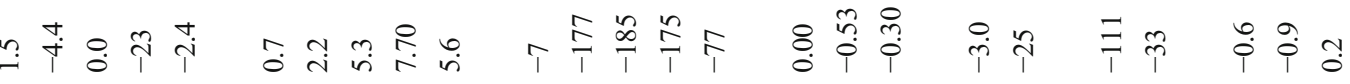

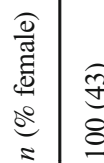

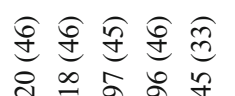

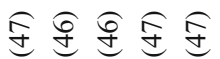

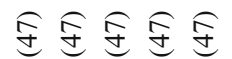

㐫导 $\stackrel{\infty}{ \pm}$

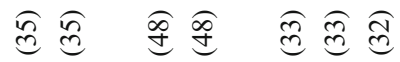

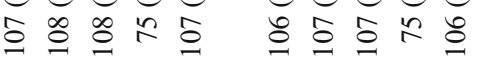
สু

ซ

ले

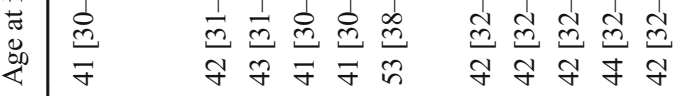

需需需

命

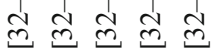

党

ช্유 i

ซृष

总

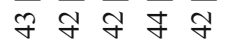

Ұ $\vec{F}$

$\stackrel{\infty}{\infty} \stackrel{\infty}{n}$

ले टे ले ले

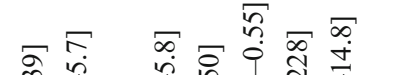

क ๙

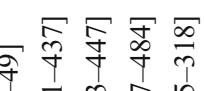

ॠँ छे

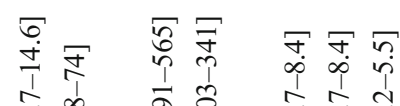

ㄷำ

స్ల

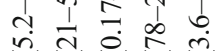

चे mo 0

도응

这这

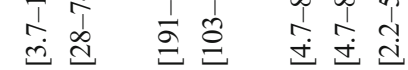

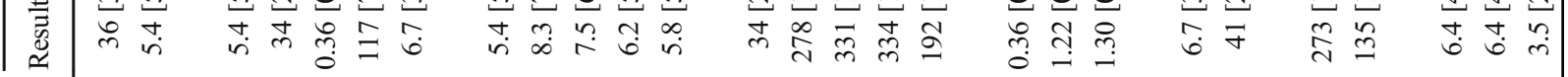

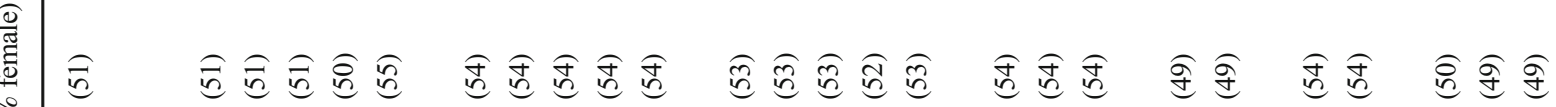

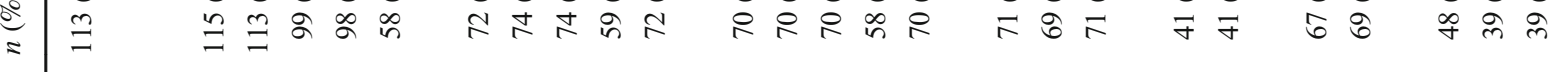

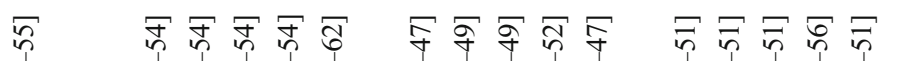

¿े

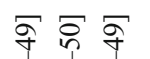

$\infty \infty$

舫

वे ते ते

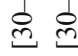

वे टे

$8 \pi \sqrt{n}$

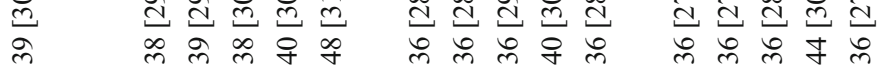

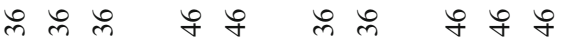

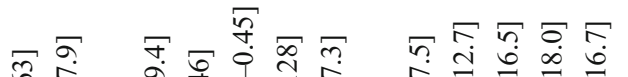

๘

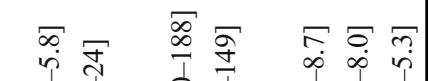

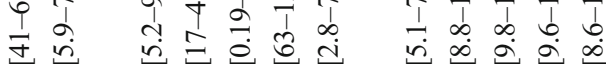

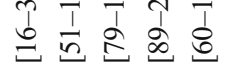

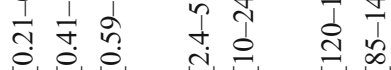

r.

in

ํㅟ कू ूू

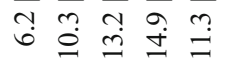

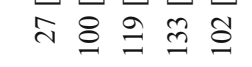

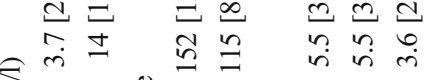

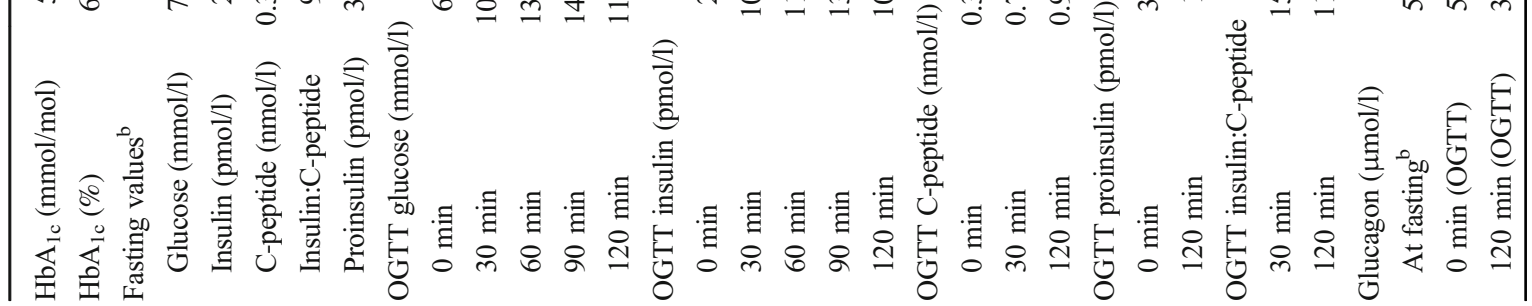




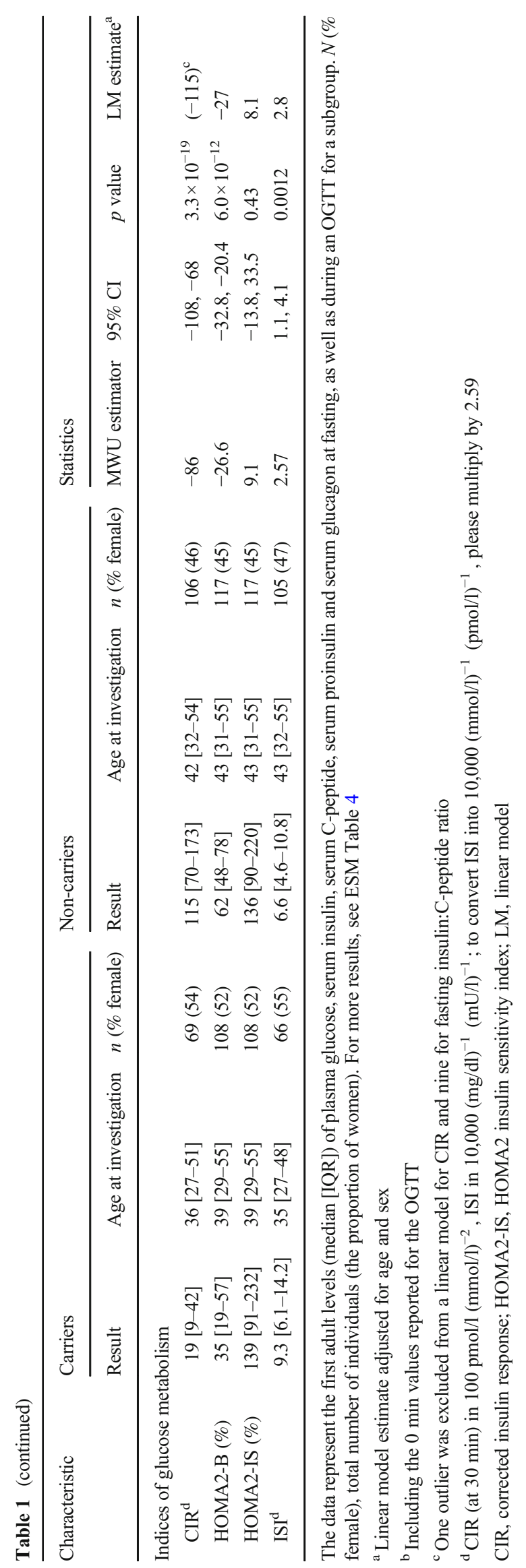




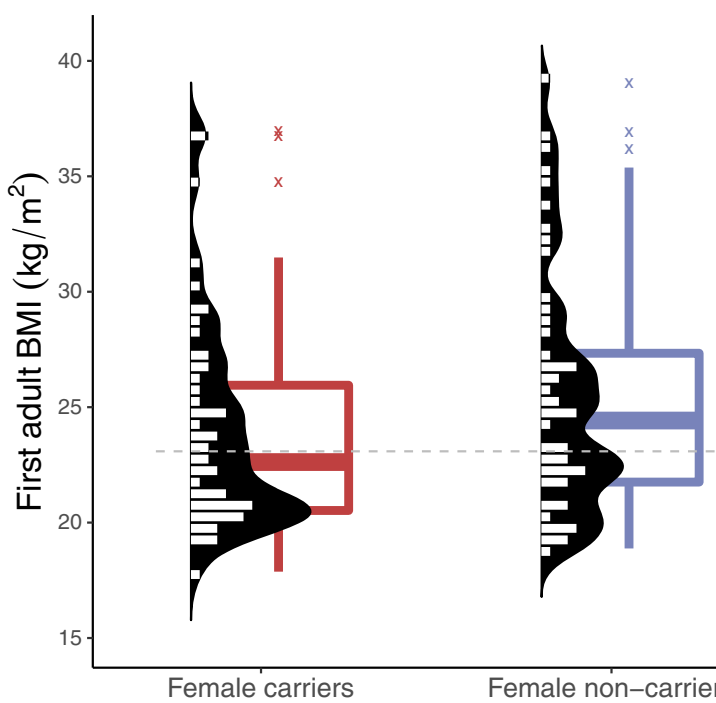

Fig. 2 First adult BMI illustrated by a boxplot and overlapping bean plot for female and male carriers and non-carriers of the HNF1A p.(Gly292fs) variant. Each observation is plotted by a short horizontal line (double

'non-diabetic' BMI (last measurement before diabetes or last ever in case of no diabetes): the median BMI of the carriers ( $n$ $=51)$ vs age- and sex-matched non-carriers $(n=51)$ was $21.2 \mathrm{vs}$ $22.1 \mathrm{~kg} / \mathrm{m}^{2}$ (MWU estimate $-1.4 \mathrm{~kg} / \mathrm{m}^{2}, p=0.11$, matched for the closest possible age, median age 18 vs 21 ).

Of note, the weight difference was equally reflected in fat and lean body mass. In linear models adjusted for sex, age and height, the carriers had $3.0 \mathrm{~kg}$ lower body fat mass $(p=0.0029)$, and $1.6 \mathrm{~kg}$ lower lean body mass $(p=0.049, \mathrm{NS})$. The difference in fat mass was significant only in men (ESM Table 6).

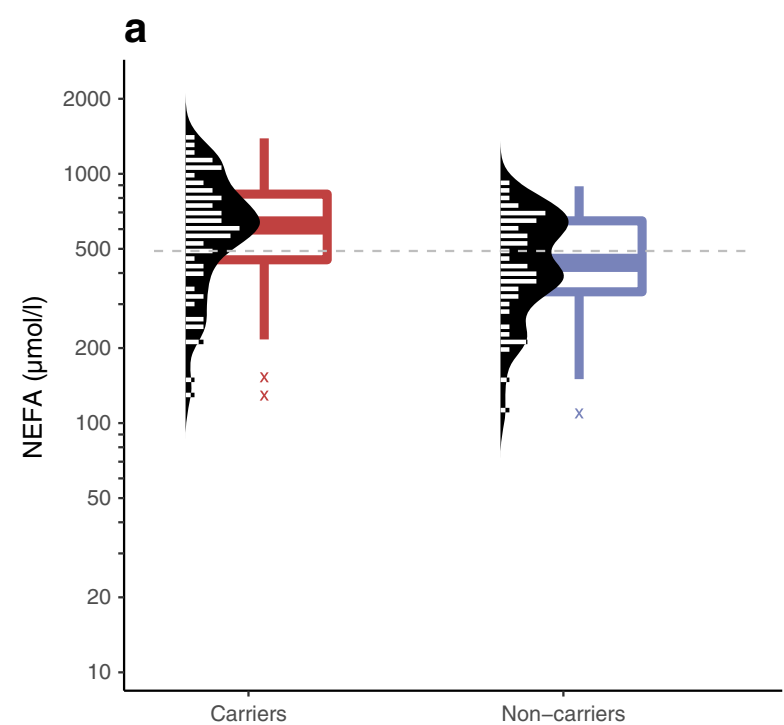

Fig. 3 First measurements in adult age of NEFA at fasting (a) and at 120 min during an OGTT (b) in carriers and non-carriers of the HNF1A p.(Gly292fs) variant. Each observation is plotted by a short horizontal line (double width symbolises two samples with the same value, etc.); the dashed grey lines represent medians. Also, a sex- and age-adjusted log-
We hypothesised that insulin deficiency associated with the HNF1A defect would lead to increased lipolysis. Accordingly, the carriers had higher levels of NEFA than the non-carriers both at fasting (median [IQR] 621 [452-829] vs 441 [340648] $\mu \mathrm{mol} / 1$, MWU: $p=0.0039, n=64 \mathrm{vs} 50$ ) and at $120 \mathrm{~min}$ (117 [80-177] vs 64 [45-91] $\mu \mathrm{mol} / 1, \mathrm{MWU}: p=3.1 \times 10^{-5}, n$ $=46$ vs 47 ; Fig. 3 ).

The groups had similar lipid levels except for HDLcholesterol concentration, which was higher in male carriers than non-carriers (median [IQR] 1.41 [1.14-1.54] vs 1.20

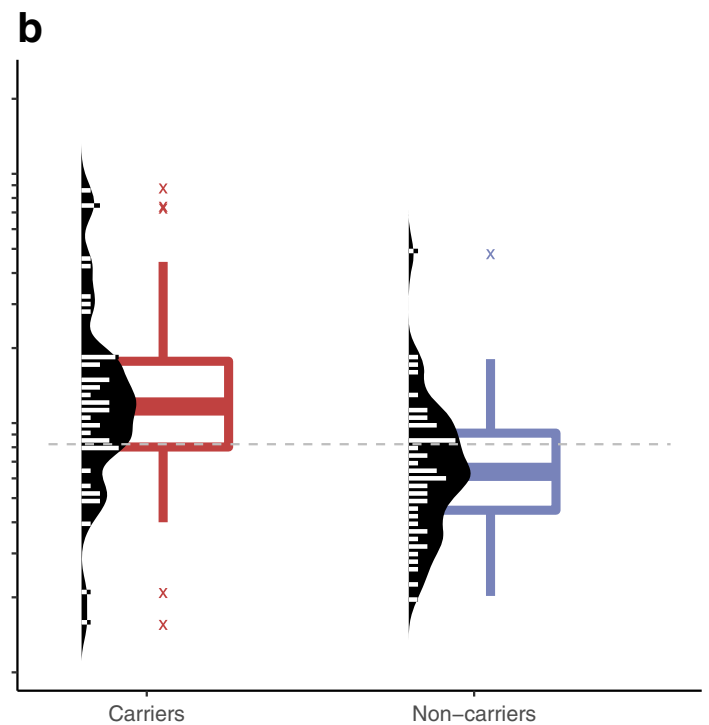

transformed linear regression model implied lower NEFA levels among the carriers compared with the non-carriers both at fasting $(p=0.00050)$ and at $120 \mathrm{~min}\left(p=2.2 \times 10^{-7}\right)$ after excluding the outliers marked with ' $\mathrm{X}$ '. One non-carrier outlier with fasting NEFA $>2000 \mu \mathrm{mol} / 1$ was excluded from the figure 
[1.05-1.38], $p=0.0051)$ (ESM Tables 4, 6). Apo-CIII levels were similar (ESM Table 6).

Glucagon Impaired suppression of glucagon secretion by glucose has been reported in HNF1A-MODY [32]. In our families, glucagon levels were similar in carriers and noncarriers, both at fasting and at $120 \mathrm{~min}$ (Fig. 4, Table 1), questioning a direct effect of the variant on alpha cells. Unfortunately, only one of the carriers with glucagon data was free of diabetes at sampling.

Urine threshold for glucose The urine threshold for glucose did not clearly differ between the carriers and the non-carriers (data in the ESM Results p. 6).

Is there a cut-off for insulin or C-peptide to exclude MODY? The highest insulin levels in our carriers were slightly below $400 \mathrm{pmol} / \mathrm{l}$ after age 35, and up to $567 \mathrm{pmol} / 1 \mathrm{during}$ normoglycaemia and $475 \mathrm{pmol} / \mathrm{l}$ during dysglycaemia in younger carriers. Fasting C-peptide was below $1.0 \mathrm{nmol} / 1$ in all carriers irrespective of glucose tolerance and age, but postchallenge concentrations reached $3.02 \mathrm{nmol} / 1$ in young carriers and $2.4 \mathrm{nmol} / \mathrm{l}$ in $>35$-year-old carriers with dysglycaemia. On the other hand, the all-time lowest fasting C-peptide levels typically exceeded $0.2 \mathrm{nmol} / 1$ ( $79 \%$ of the measurements) but had been $<0.1 \mathrm{nmol} / 1$ in $11 / 125$ carriers.

The participation rate and the age at entering the study The three large families (B, C and D) constituted the major study population, with detailed data on multigenerational family structure. To ensure that participation bias did not affect the results, we evaluated the participation rate, i.e., the proportion of the participants of all potential participants (the actual participants and their non-participating siblings and the carriers' offspring), in them. The overall participation rate was $74 \%$ in the main and $85 \%$ in the siblings-only analysis. The corresponding figures were $84 \%$ and $94 \%$ among those born in 1975-2000. Most siblings of those born since the 1960s participated (ESM Fig. 2a). The carrier:non-carrier ratio was 53\%:47\%, close to the expected 50\%:50\% ( $p=0.15)$.

The median age at the first visit depended on the decade of birth (ESM Fig. 2b), and has gradually fallen from around 70 years among those born in the 1920 s, to under 20 years in those born in the 1980 s or later. Thus, the majority of those born before the 1980s had been diagnosed with diabetes already at the first visit, whereas most carriers born later had been free of diabetes at their first visit.

\section{Discussion}

In this family-based study comparing relatives with and without the heterozygous $H N F 1 A$ variant p.(Gly292fs), we show that although half of the variant carriers progress to overt diabetes by the age of 23 years, $13 \%$ are free of diabetes at the age of 50. In addition, T2D-PRS modified the age at onset of diabetes. The relative insulin deficiency is characterised by hyperglycaemia, lipolysis and markedly lower adult BMI. Studying individuals based on genotype rather than phenotype bypasses some problems with ascertainment bias and offers a more realistic view of the manifestations of the gene variant.

Presentation at young age has been one of the cornerstones of the diagnosis of MODY. The diagnosis age of the probands in the original studies [3, 4, 33] guided the early clinical criteria to include age at onset before 25 years in at least 1-2 family members [34]. In a larger subsequent series, $70 \%$ of the participants with HNF1A-MODY were diagnosed with diabetes by the age of 25 and $85 \%$ by 35 years [35]. However, these figures only pertain to individuals who developed diabetes, and mostly were clinically suspected to have MODY, biasing towards a more severe phenotype. In contrast, we invited all relatives regardless of their glycaemic status to participate in the study, combining retrospective, cross-sectional and prospective follow-up data. The penetrance was lower than
Fig. 4 Fasting glucagon plotted against 120 min glucagon in 43 carriers (red square boxes) and 38 non-carriers (blue circles) of the HNF1A p.(Gly292fs) variant, with a regression line for the combined group $\left(p=4.5 \times 10^{-12}, r^{2}\right.$ $0.45)$. fS-glucagon, fasting serum glucagon; S-glucagon, serum glucagon

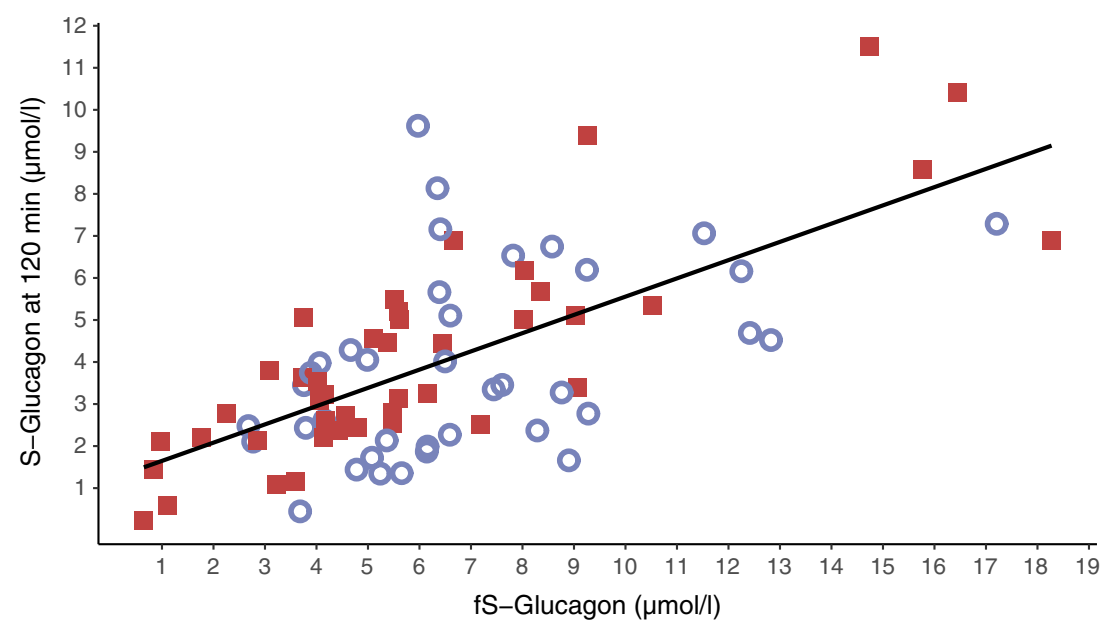


in the clinical series: $57 \%$ of carriers had converted to diabetes before the age of 25 and $70 \%$ by 35 years. Of note, $13 \%$ were still free of diabetes at the age of 50 .

While we observed no effect of BMI, insulin sensitivity, parental carrier status or sex on age at diagnosis, the T2DPRS, based on 210 known risk loci for type 2 diabetes, advanced the onset of diabetes moderately. In a Cox model, $+1 \mathrm{SD}$ of T2D-PRS increased the risk of diabetes by $28 \%$, whereas in a linear regression model +1 SD of T2D-PRS was associated with a 3 year earlier diagnosis of HNF1A-diabetes. Previously, using 17-SNP T2D-PRS, Lango Allen and colleagues reported that each additional SNP was associated with a 0.35 year earlier diagnosis in HNF1A-MODY [36]. Our data support adding HNF1A-MODY to the diseases in which the polygenic risk score modulates the manifestation of monogenic variants [37].

Identification of carriers before they developed diabetes enabled us to explore early phenotypes and to compare them with genetically and environmentally matched control participants, i.e., related non-carriers. The high participation rate and similar T2D-PRS distribution in the groups minimised the ascertainment bias. Untargeted population-wide sequencing might further reduce it [38], considering that a suspicion of MODY had motivated the genetic testing of the first members. Also, the higher T2D-PRS than in the background population might have aided in recognising the high familial prevalence of diabetes. However, as MODY often presents with slowly progressing asymptomatic hyperglycaemia, diagnostic measures in a population setting (like clinical diagnosis, $\mathrm{HbA}_{1 \mathrm{c}}$ or $\mathrm{FPG}$ ) are not sensitive enough to define the time of conversion [27]. Active population screening by an OGTT would be crucial to recognise those with undiagnosed diabetes. For example, among a middle-aged population, screening revealed undiagnosed diabetes in $6.4 \%$ of women and $11.6 \%$ of men in Finland [39], and in 5.2\% of women and $10.4 \%$ of men in Spain [40]. We also previously reported that the carriers born after 1975 were diagnosed with diabetes earlier than former generations, presumably due to increased awareness and screening [27]. An additional covariate of birth year also increased the statistical power of the regression models on T2D-PRS.

We could not identify clinical factors that predicted the age of conversion to diabetes. Maternal inheritance and parental age at onset of diabetes have previously been linked to the offspring's age at diagnosis [36, 41, 42], but our study found no support for this. It has been suggested that the parent of origin plays no role as long as the offspring is not unexposed to maternal hyperglycaemia during pregnancy [41]. Therefore, maternal inheritance might only contribute to the onset age of the offspring indirectly through gestational hyperglycaemia. We also found no support for the hypothesis of insulin resistance or high BMI lowering the age at onset, agreeing with a previous report [36]. In contrast, the observed association between lower BMI and earlier diabetes among young carriers who have undergone active screening for diabetes could reflect impaired beta cell function and decreased anabolic effects of insulin, which is reinforced by the disappearance of the association by adjusting for $\mathrm{C}$ peptide.

Individuals with HNF1A-MODY are leaner than individuals with type 2 diabetes $[9,12,14,43-46]$. Whether the pathogenic HNF1A variants are associated with body mass in general has largely been ignored, although variant carriers have been leaner than individuals with type 1 diabetes and control individuals [14, 21, 43, 47]. Therefore, we also explored association with body composition. Variant carriers were $\sim 5 \mathrm{~kg}\left(\sim 2 \mathrm{~kg} / \mathrm{m}^{2}\right)$ leaner than their relatives, whereas adult height was similar. The difference in BMI was similar when age- and sex-matched control participants from the PPPBotnia Study were used for the comparison $\left(-1.67 \mathrm{~kg} / \mathrm{m}^{2}\right)$, which speaks against a collider bias.

Moreover, the differences in fat mass $(3.0 \mathrm{~kg})$ and lean body mass $(2.6 \mathrm{~kg})$ were of a similar magnitude between the carriers and non-carriers in this study, but only the fat mass difference reached statistical significance. As BMI was a stronger predictor of insulin sensitivity (ISI) than the carrier status (data not shown), HNF1A seems to indirectly affect insulin sensitivity through lowering BMI. Indeed, a better insulin sensitivity has been shown in carriers, whose mean BMI was lower than that of their comparators [14], and vice versa [15], while the difference in insulin sensitivity disappeared when matched for BMI [16]. Because the difference in body weight was attenuated after excluding measurements after the diagnosis of diabetes, the difference might result from progressive insulin deficiency and anabolic effect of insulin [48] or loss of energy due to glucosuria (or both).

HNF1A-MODY has been associated with a lower renal threshold for glucose and glucosuria [3, 29, 49, 50], which could result from insulin deficiency or be a direct effect of $H N F 1 A$ through reduced renal expression of SLC5A2 (also known as SGLT2 for sodium-glucose cotransporter 2) [50, 51], a key transporter involved in tubular glucose reabsorption. In vitro studies indicate that the postprandial insulin surge enhances glucose reabsorption in kidneys [52]. Thus, postprandial insulin deficiency might promote glucosuria, but human data are lacking. In a previous study, all individuals with a pathogenic HNF1A variant and a peak plasma glucose $>8.4 \mathrm{mmol} / \mathrm{l}$ demonstrated post-OGTT glucosuria [29], but our study did not replicate this finding. A combination of a graded intravenous glucose infusion with an insulin infusion, to yield matched glucose and insulin concentrations in carriers and non-carriers, might provide a definitive answer.

Consistent with insulin deficiency and less inhibition of lipolysis [53], the carriers had significantly higher NEFA levels than non-carriers both at fasting and after an OGTT. Increased lipolytic activity might contribute to the differences in body weight and fat mass. On the other hand, free circulating NEFA could in turn worsen beta cell function $[54,55]$. 
As hyperglucagonaemia has been reported in individuals with type 1 and 2 diabetes as well as in HNF1A-MODY [32, 56, 57], we evaluated a possible relationship between lipolysis and excess glucagon, despite only vague previous data [58]. Despite the differences in glucose and insulin responses, the glucagon level was similar in the carriers and non-carriers, suggesting relative hyperglucagonaemia in the carriers (hyperglycaemia should acutely suppress glucagon secretion). Unfortunately, the crosssectional comparison of mostly carriers with diabetes and noncarriers without diabetes precluded a reliable comparison. At present, we can only speculate that while hyperglycaemia is not a potent enough suppressor of glucagon secretion, the degree of insulin secretion was sufficient to inhibit excess glucagon secretion. Notably, a recent study on human islets with an HNF1A defect observed an abrogated rather than increased glucagon response from alpha cells [59].

HNF1A defects lead to insulin deficiency, and expectedly the carriers had lower serum insulin concentrations than the noncarriers. Confirming results from previous studies and suggestive of an impaired first-phase insulin secretion, the difference in insulin levels was most clear during an OGTT and peaked at $30 \mathrm{~min}[14,15,21]$. Interestingly, both at fasting and during OGTT, the difference in insulin levels outweighed that in proinsulin or C-peptide levels. The higher insulin:C-peptide ratio in the carriers might be attributed to a difference in hepatic insulin clearance. Perhaps the carriers, who are leaner and thus presumably less insulin-resistant than non-carriers, can extract proportionally more insulin, or, alternatively, the HNF1A defect directly affects hepatic function [60].

Conclusions In this study based on ascertainment of participants by genotype rather than clinical presentation, one-third of the heterozygous carriers of the HNF1A p.(Gly292fs) variant were free of diabetes at the age of 33 , and $13 \%$ at the age of 50 years. The polygenic risk for type 2 diabetes lowered the age at onset of carriers. We could not identify clinical factors affecting the age at conversion, but could exclude major effects of sex, BMI, insulin sensitivity and parental carrier status. Between the carriers and non-carriers, the fasting and OGTT measurements of serum insulin were more discriminative than those of serum C-peptide. The carriers were leaner than non-carriers and had higher lipolytic activity.

Supplementary Information The online version contains peer-reviewed but unedited supplementary material available at https://doi.org/10.1007/ s00125-021-05631-z.

Acknowledgements We thank M. Lehto for coordinating the initial study of families B, C and D [14]. The skilful assistance of the Botnia and FINNMODY study groups is gratefully acknowledged.

Data availability Considering issues of patient confidentiality and restrictions in IRB permissions, original data can only be available through specific request and material transfer agreement following the EU regulations.
Funding Open Access funding provided by University of Helsinki including Helsinki University Central Hospital. The Botnia, FINNMODY and PPP-Botnia studies have been financially supported by grants from Folkhälsan Research Foundation, the Sigrid Juselius Foundation, the Academy of Finland (grants no. 263401, 267882, 312063,336822 to LCG; 312072 and 336826 to TT), the University of Helsinki, the Nordic Center of Excellence in Disease Genetics, the EU (EXGENESIS, MOSAIC FP7-600914), the Ollqvist Foundation, the Swedish Cultural Foundation in Finland, the Finnish Diabetes Research Foundation, the Foundation for Life and Health in Finland, the Signe and Ane Gyllenberg Foundation, the Finnish Medical Society, the Paavo Nurmi Foundation, State Research Funding via the Helsinki University Hospital, the Perklén Foundation, Närpes Health Care Foundation and the Ahokas Foundation. These studies have also been supported by the Ministry of Education in Finland, the Municipal Health Care Center and Hospital in Jakobstad, and Health Care Centers in Vasa, Närpes and Korsholm.

Authors' relationships and activities The authors declare that there are no relationships or activities that might bias, or be perceived to bias, their work.

Contribution statement JLTK, ER, LS, BI, PK, TT, LH and LCG performed the clinical study and laboratory analyses. JLTK, OPD, PJM and TT analysed the data. TT and LCG supervised the project. JLTK, PJM, LCG, OPD and TT wrote the manuscript. All authors revised and approved the manuscript. TT and JLTK act as guarantors of this study.

Open Access This article is licensed under a Creative Commons Attribution 4.0 International License, which permits use, sharing, adaptation, distribution and reproduction in any medium or format, as long as you give appropriate credit to the original author(s) and the source, provide a link to the Creative Commons licence, and indicate if changes were made. The images or other third party material in this article are included in the article's Creative Commons licence, unless indicated otherwise in a credit line to the material. If material is not included in the article's Creative Commons licence and your intended use is not permitted by statutory regulation or exceeds the permitted use, you will need to obtain permission directly from the copyright holder. To view a copy of this licence, visit http://creativecommons.org/licenses/by/4.0/.

\section{References}

1. Misra S, Owen KR (2018) Genetics of Monogenic Diabetes: Present Clinical Challenges. Curr Diab Rep 18(12):141. https:// doi.org/10.1007/s11892-018-1111-4

2. De Franco E (2020) From Biology to Genes and Back Again: Gene Discovery for Monogenic Forms of Beta-Cell Dysfunction in Diabetes. J Mol Biol 432(5):1535-1550. https://doi.org/10.1016/j. jmb.2019.08.016

3. Tattersall RB (1974) Mild familial diabetes with dominant inheritance. Q J Med 43(170):339-357

4. Tattersal RB, Fajans SS (1975) Prevalence of diabetes and glucose intolerance in 199 offspring of thirty-seven conjugal diabetic parents. Diabetes 24(5):452-462. https://doi.org/10.2337/diab.24. 5.452

5. Froguel P, Vaxillaire M, Sun F et al (1992) Close linkage of glucokinase locus on chromosome $7 p$ to early-onset non-insulindependent diabetes mellitus. Nature 356(6365):162-164. https:// doi.org/10.1038/356162a0 
6. Vionnet N, Stoffel M, Takeda J et al (1992) Nonsense mutation in the glucokinase gene causes early-onset non-insulin-dependent diabetes mellitus. Nature 356(6371):721-722. https://doi.org/10. $1038 / 356721 \mathrm{a} 0$

7. Yamagata K, Oda N, Kaisaki PJ et al (1996) Mutations in the hepatocyte nuclear factor-1alpha gene in maturity-onset diabetes of the young (MODY3). Nature 384(6608):455-458. https://doi. org $/ 10.1038 / 384455 \mathrm{a} 0$

8. Yamagata K, Furuta H, Oda N et al (1996) Mutations in the hepatocyte nuclear factor-4alpha gene in maturity-onset diabetes of the young (MODY1). Nature 384(6608):458-460. https://doi.org/10. 1038/384458a0

9. Shields BM, McDonald TJ, Ellard S, Campbell MJ, Hyde C, Hattersley AT (2012) The development and validation of a clinical prediction model to determine the probability of MODY in patients with young-onset diabetes. Diabetologia 55(5):1265-1272. https:// doi.org/10.1007/s00125-011-2418-8

10. Shields B, Colclough K (2017) Towards a systematic nationwide screening strategy for MODY. Diabetologia 60(4):609-612. https:// doi.org/10.1007/s00125-017-4213-7

11. Shields BM, Hicks S, Shepherd MH, Colclough K, Hattersley AT, Ellard S (2010) Maturity-onset diabetes of the young (MODY): how many cases are we missing? Diabetologia 53(12):25042508. https://doi.org/10.1007/s00125-010-1799-4

12. Bellanné-Chantelot C, Lévy DJ, Carette C et al (2011) Clinical characteristics and diagnostic criteria of maturity-onset diabetes of the young (MODY) due to molecular anomalies of the HNF1A gene. J Clin Endocrinol Metab 96(8):E1346-E1351. https://doi. org/10.1210/jc.2011-0268

13. Thanabalasingham G, Pal A, Selwood MP et al (2012) Systematic assessment of etiology in adults with a clinical diagnosis of youngonset type 2 diabetes is a successful strategy for identifying maturity-onset diabetes of the young. Diabetes Care 35(6):12061212. https://doi.org/10.2337/dc11-1243

14. Lehto M, Tuomi T, Mahtani MM et al (1997) Characterization of the MODY3 phenotype. Early-onset diabetes caused by an insulin secretion defect. J Clin Invest 99(4):582-591. https://doi.org/10. 1172/JCI119199

15. Vaxillaire M, Pueyo ME, Clément K et al (1999) Insulin secretion and insulin sensitivity in diabetic and non-diabetic subjects with hepatic nuclear factor-1alpha (maturity-onset diabetes of the young-3) mutations. Eur J Endocrinol 141(6):609-618. https:// doi.org/10.1530/eje.0.1410609

16. Brackenridge A, Pearson ER, Shojaee-Moradie F, Hattersley AT, Russell-Jones D, Umpleby AM (2006) Contrasting insulin sensitivity of endogenous glucose production rate in subjects with hepatocyte nuclear factor-1beta and -1alpha mutations. Diabetes 55(2): 405-411. https://doi.org/10.2337/diabetes.55.02.06.db05-1019

17. Pearson ER, Liddell WG, Shepherd M, Corrall RJ, Hattersley AT (2000) Sensitivity to sulphonylureas in patients with hepatocyte nuclear factor-1alpha gene mutations: evidence for pharmacogenetics in diabetes. Diabet Med 17(7):543-545. https://doi.org/10.1046/ j.1464-5491.2000.00305.x

18. Sagen JV, Pearson ER, Johansen A et al (2005) Preserved insulin response to tolbutamide in hepatocyte nuclear factor-1alpha mutation carriers. Diabet Med 22(4):406-409. https://doi.org/10.1111/j. 1464-5491.2005.01439.x

19. Groop L, Forsblom C, Lehtovirta M et al (1996) Metabolic consequences of a family history of NIDDM (the Botnia study): evidence for sex-specific parental effects. Diabetes 45(11):1585-1593. https://doi.org/10.2337/diab.45.11.1585

20. Lyssenko V, Almgren P, Anevski D et al (2005) Predictors of and longitudinal changes in insulin sensitivity and secretion preceding onset of type 2 diabetes. Diabetes 54(1):166-174. https://doi.org/ 10.2337/diabetes.54.1.166
21. Tripathy D, Carlsson AL, Lehto M, Isomaa B, Tuomi T, Groop L (2000) Insulin secretion and insulin sensitivity in diabetic subgroups: studies in the prediabetic and diabetic state. Diabetologia 43(12):1476-1483. https://doi.org/10.1007/ s001250051558

22. Isomaa B, Forsén B, Lahti K et al (2010) A family history of diabetes is associated with reduced physical fitness in the Prevalence, Prediction and Prevention of Diabetes (PPP)-Botnia study. Diabetologia 53(8):1709-1713. https://doi.org/10.1007/s00125010-1776-y

23. Mahajan A, Taliun D, Thurner M et al (2018) Fine-mapping type 2 diabetes loci to single-variant resolution using high-density imputation and islet-specific epigenome maps. Nat Genet 50(11):15051513. https://doi.org/10.1038/s41588-018-0241-6

24. Matthews DR, Hosker JP, Rudenski AS, Naylor BA, Treacher DF, Turner RC (1985) Homeostasis model assessment: insulin resistance and beta-cell function from fasting plasma glucose and insulin concentrations in man. Diabetologia 28(7):412-419. https://doi. org/10.1007/BF00280883

25. Levy JC, Matthews DR, Hermans MP (1998) Correct homeostasis model assessment (HOMA) evaluation uses the computer program. Diabetes Care 21(12):2191-2192. https://doi.org/10.2337/diacare. 21.12.2191

26. Matsuda M, DeFronzo RA (1999) Insulin sensitivity indices obtained from oral glucose tolerance testing: comparison with the euglycemic insulin clamp. Diabetes Care 22(9):1462-1470. https://doi. org/10.2337/diacare.22.9.1462

27. Kettunen JLT, Tuomi T (2020) Human Physiology of Genetic Defects Causing Beta-cell Dysfunction. J Mol Biol 432(5):1579 1598. https://doi.org/10.1016/j.jmb.2019.12.038

28. Saari A, Sankilampi U, Hannila M-L, Kiviniemi V, Kesseli K, Dunkel L (2011) New Finnish growth references for children and adolescents aged 0 to 20 years: Length/height-for-age, weight-forlength/height, and body mass index-for-age. Ann Med 43(3):235248. https://doi.org/10.3109/07853890.2010.515603

29. Stride A, Ellard S, Clark P et al (2005) Beta-cell dysfunction, insulin sensitivity, and glycosuria precede diabetes in hepatocyte nuclear factor-1alpha mutation carriers. Diabetes Care 28(7):1751-1756. https://doi.org/10.2337/diacare.28.7.1751

30. Pearson ER, Velho G, Clark P et al (2001) beta-cell genes and diabetes: quantitative and qualitative differences in the pathophysiology of hepatic nuclear factor-1alpha and glucokinase mutations. Diabetes 50(Suppl 1):S101-S107. https://doi.org/10.2337/diabetes. 50.2007.s101

31. Bonadonna RC, Boselli L, Dei Cas A, Trombetta M (2018) Methods to assess in vivo insulin sensitivity and insulin secretion. In: Bonora E, DeFronzo R (eds) Diabetes. Epidemiology, genetics, pathogenesis, diagnosis, prevention, and treatment. Springer International Publishing, Cham, pp 1-51

32. Østoft SH, Bagger JI, Hansen T et al (2014) Incretin effect and glucagon responses to oral and intravenous glucose in patients with maturity-onset diabetes of the young-type 2 and type 3. Diabetes 63(8):2838-2844. https://doi.org/10.2337/db13-1878

33. Fajans SS, Bell GI, Polonsky KS (2001) Molecular mechanisms and clinical pathophysiology of maturity-onset diabetes of the young. N Engl J Med 345(13):971-980. https://doi.org/10.1056/ NEJMra002168

34. Stride A, Hattersley AT (2002) Different genes, different diabetes: lessons from maturity-onset diabetes of the young. Ann Med 34(3): 207-216

35. Patel KA, Kettunen J, Laakso M et al (2017) Heterozygous RFX6 protein truncating variants are associated with MODY with reduced penetrance. Nat Commun 8(1):888. https://doi.org/10.1038/ s41467-017-00895-9

36. Lango Allen H, Johansson S, Ellard S et al (2010) Polygenic risk variants for type 2 diabetes susceptibility modify age at diagnosis in 
monogenic HNF1A diabetes. Diabetes 59(1):266-271. https://doi. org/10.2337/db09-0555

37. Fahed AC, Wang M, Homburger JR et al (2020) Polygenic background modifies penetrance of monogenic variants for tier 1 genomic conditions. Nat Commun 11(1):3635. https://doi.org/10.1038/ s41467-020-17374-3

38. Wright CF, West B, Tuke M et al (2019) Assessing the Pathogenicity, Penetrance, and Expressivity of Putative DiseaseCausing Variants in a Population Setting. Am J Hum Genet 104(2):275-286. https://doi.org/10.1016/j.ajhg.2018.12.015

39. Saaristo T, Peltonen M, Lindström J et al (2005) Cross-sectional evaluation of the Finnish Diabetes Risk Score: a tool to identify undetected type 2 diabetes, abnormal glucose tolerance and metabolic syndrome. Diab Vasc Dis Res 2(2):67-72. https://doi.org/10. 3132/dvdr.2005.011

40. Salinero-Fort MA, Burgos-Lunar C, Lahoz C et al (2016) Performance of the Finnish Diabetes Risk Score and a Simplified Finnish Diabetes Risk Score in a Community-Based, CrossSectional Programme for Screening of Undiagnosed Type 2 Diabetes Mellitus and Dysglycaemia in Madrid, Spain: The SPREDIA-2 Study. PLoS One 11(7):e0158489. https://doi.org/ 10.1371/journal.pone.0158489

41. Klupa T, Warram JH, Antonellis A et al (2002) Determinants of the Development of Diabetes (Maturity-Onset Diabetes of the Young3 ) in Carriers of HNF-1 $\alpha$ Mutations: Evidence for parent-of-origin effect. Diabetes Care 25(12):2292-2301. https://doi.org/10.2337/ diacare.25.12.2292

42. Stride A, Shepherd M, Frayling TM, Bulman MP, Ellard S, Hattersley AT (2002) Intrauterine hyperglycemia is associated with an earlier diagnosis of diabetes in HNF-1alpha gene mutation carriers. Diabetes Care 25(12):2287-2291. https://doi.org/10. 2337/diacare.25.12.2287

43. Nowak N, Hohendorff J, Solecka I et al (2015) Circulating ghrelin level is higher in HNF1A-MODY and GCK-MODY than in polygenic forms of diabetes mellitus. Endocrine 50(3):643-649. https:// doi.org/10.1007/s12020-015-0627-5

44. Ludvigsson J, Carlsson A, Forsander G et al (2012) C-peptide in the classification of diabetes in children and adolescents. Pediatr Diabetes 13(1):45-50. https://doi.org/10.1111/j.1399-5448.2011. 00807.x

45. McDonald TJ, McEneny J, Pearson ER et al (2012) Lipoprotein composition in HNF1A-MODY: differentiating between HNF1AMODY and type 2 diabetes. Clin Chim Acta 413(9-10):927-932. https://doi.org/10.1016/j.cca.2012.02.005

46. Ekholm E, Shaat N, Holst JJ (2012) Characterization of beta cell and incretin function in patients with MODY1 (HNF4A MODY) and MODY3 (HNF1A MODY) in a Swedish patient collection. Acta Diabetol 49(5):349-354. https://doi.org/10.1007/s00592011-0312-y

47. Besser REJ, Shepherd MH, McDonald TJ et al (2011) Urinary Cpeptide creatinine ratio is a practical outpatient tool for identifying hepatocyte nuclear factor 1-\{alpha\}/hepatocyte nuclear factor 4\{alpha\} maturity-onset diabetes of the young from long-duration type 1 diabetes. Diabetes Care 34(2):286-291. https://doi.org/10. 2337/dc10-1293
48. Petersen MC, Shulman GI (2018) Mechanisms of Insulin Action and Insulin Resistance. Physiol Rev 98(4):2133-2223. https://doi. org/10.1152/physrev.00063.2017

49. Menzel R, Kaisaki PJ, Rjasanowski I, Heinke P, Kerner W, Menzel $\mathrm{S}$ (1998) A low renal threshold for glucose in diabetic patients with a mutation in the hepatocyte nuclear factor-1alpha (HNF-1alpha) gene. Diabet Med 15(10):816-820. https://doi.org/10.1002/(SICI) 1096-9136(199810)15:10<816::AID-DIA714>3.0.CO;2-P

50. Pontoglio M, Prié D, Cheret $\mathrm{C}$ et al (2000) HNF1 $\alpha$ controls renal glucose reabsorption in mouse and man. EMBO Rep 1(4):359-365. https://doi.org/10.1093/embo-reports/kvd071

51. Takesue H, Hirota T, Tachimura M, Tokashiki A, Ieiri I (2018) Nucleosome Positioning and Gene Regulation of the SGLT2 Gene in the Renal Proximal Tubular Epithelial Cells. Mol Pharmacol 94(3):953-962. https://doi.org/10.1124/mol.118. 111807

52. Ferrannini E (2017) Sodium-Glucose Co-transporters and Their Inhibition: Clinical Physiology. Cell Metab 26(1):27-38. https:// doi.org/10.1016/j.cmet.2017.04.011

53. Chakrabarti P, Kim JY, Singh M et al (2013) Insulin Inhibits Lipolysis in Adipocytes via the Evolutionarily Conserved mTORC1-Egr1-ATGL-Mediated Pathway. Mol Cell Biol 33(18): 3659-3666. https://doi.org/10.1128/MCB.01584-12

54. Oh YS, Bae GD, Baek DJ, Park E-Y, Jun H-S (2018) Fatty AcidInduced Lipotoxicity in Pancreatic Beta-Cells During Development of Type 2 Diabetes. Front Endocrinol 9:384. https://doi.org/10. 3389/fendo.2018.00384

55. Boden G (2011) Obesity, insulin resistance and free fatty acids. Curr Opin Endocrinol Diabetes Obes 18(2):139-143. https://doi. org/10.1097/MED.0b013e3283444b09

56. Finan B, Capozzi ME, Campbell JE (2020) Repositioning Glucagon Action in the Physiology and Pharmacology of Diabetes. Diabetes 69(4):532-541. https://doi.org/10.2337/dbi190004

57. Yosten GLC (2018) Alpha cell dysfunction in type 1 diabetes. Peptides 100:54-60. https://doi.org/10.1016/j.peptides.2017.12. 001

58. Galsgaard KD, Pedersen J, Knop FK, Holst JJ, Wewer Albrechtsen NJ (2019) Glucagon Receptor Signaling and Lipid Metabolism. Front Physiol 10:413. https://doi.org/10.3389/fphys.2019.00413

59. Haliyur R, Tong X, Sanyoura M et al (2019) Human islets expressing HNF1A variant have defective $\beta$ cell transcriptional regulatory networks. J Clin Invest 129(1):246-251. https://doi.org/10.1172/ JCI121994

60. Servitja J-M, Pignatelli M, Maestro MÁ et al (2009) Hnfl $\alpha$ (MODY3) Controls Tissue-Specific Transcriptional Programs and Exerts Opposed Effects on Cell Growth in Pancreatic Islets and Liver. Mol Cell Biol 29(11):2945-2959. https://doi.org/10.1128/ MCB.01389-08

Publisher's note Springer Nature remains neutral with regard to jurisdictional claims in published maps and institutional affiliations. 